\title{
Development and initial factor validation of the French Conformity to the Sport Ethic
}

\author{
Scale (CSES) \\ Sylvie Parent, Ph.D. ${ }^{1,2}$ \\ Kristine Fortier, M.A $\mathrm{A}^{1,2}$ \\ Marie-Pier Vaillancourt-Morel, Ph.D. ${ }^{2,3}$ \\ Geneviève Lessard, Ph.D. ${ }^{4,5}$ \\ Claude Goulet, Ph.D. ${ }^{1,6}$ \\ Guylaine Demers, Ph.D. ${ }^{1}$ \\ Hélène Paradis, M.Sc. ${ }^{7}$ \\ Mike Hartill, Ph.D. ${ }^{8}$
}

Corresponding author: Sylvie Parent, Ph.D., Pavillon de l'Éducation physique et des sports, 2300, rue de la Terrasse, local 2206, Université Laval, G1V 0A6, Québec, QC, Canada.

Email: sylvie.parent@fse.ulaval.ca

Funding: This work was supported by the [Social Sciences and Humanities Research Council of Canada] under Grant [108560]; and [ministère de l'Éducation et de l'Enseignement supérieur du Québec] under Grant [104153].

${ }^{1}$ Department of Physical Education, Faculty of Education, Université Laval, Québec, QC, Canada

${ }^{2}$ Interdisciplinary Research Center on Intimate Relationship Problems and Sexual Abuse (CRIPCAS), Canada

${ }^{3}$ Department of Psychology, Université de Montréal, Montréal, QC, Canada

${ }^{4}$ School of Social Work, Université Laval, Québec, Canada

${ }^{5}$ Interdisciplinary Research Center on Family Violence and Violence Against Women (CRI-VIFF), Canada

${ }^{6}$ Interuniversity Research Centre on Teaching and Teaching Profession (CRIFPE)

${ }^{7}$ Research Unit on Children's Psychosocial Maladjustment (GRIP), Université Laval, Canada

${ }^{8}$ Faculty of Sport and Physical Activity, Edge Hill University, United Kingdom 
To cite: Parent, S., Fortier, K., Vaillancourt-Morel, M-P., Lessard, G., Goulet, C., Demers, G., Paradis, H., \& Hartill, M. (accepted). Development and initial factor validation of the French Conformity to the Sport Ethic Scale (CSES). Canadian Journal of Behavioural Science.

\begin{abstract}
Coker-Cranney et al. (2018) recently stressed the need for the development and validation of a questionnaire that assesses a young athlete's level of conformity to sport ethic norms. The objective of this study was to develop and begin an initial factor validation of the Conformity to the Sport Ethic Scale (CSES), a scale assessing the conformity of teenage athletes from all competition levels to these sport ethic norms. Following the steps suggested by DeVellis (2012) for scale development and validation, a convenience sample of 1096 French-Canadian athletes between 14 and 18 years and who participated in an organized sport were recruited to partake in an online study assessing their conformity to the sport ethic. The CSES was developed to include four dimensions based on the qualitative work of Hughes and Coakley (1991), namely, selfsacrifice, striving for distinction, accepting risks/playing through pain and refusing to accept limits. To identify latent factors underlying the CSES exploratory structural equation modeling (ESEM) was performed using Mplus version 8.0. The CSES includes 20 items in three factors: striving for distinction (6 items), self-sacrifice (4 items) and refusing to accept limits (10 items). The resulting factor structure was invariant between boys and girls. Internal consistency of these subscales was acceptable. All correlations between subscales were significant. This tool is the first step to measure conformity to the Sport Ethic norms and will allow for further research in this area.
\end{abstract}

Keywords: Sport Ethic; Scale; Validation; Athletes; Sport 


\section{Public significance statement}

- It has been suggested that athletes and their environment follow a set of norms (the sport ethic) that represent what a real athlete should do, namely 1) striving for distinction, 2) making sacrifices for the game, 3) accepting risks and playing through pain, and 4) refusing to accept limits. In the current study, accepting risks and playing through pain and refusing to accept limits were not found to be distinct norms and were more related than anticipated in previous studies.

- An extreme level of conformity to the sport ethic norms have been considered as a risk factor for problems such as disordered eating, training despite injury, doping, peer aggression and violence toward athletes (e.g., abuse and maltreatment). Prior to the current research, it was not possible to clearly measure the link between these issues and sport ethics; however, these results allowed further comprehension of the aforementioned problems by developing a scale to measure conformity to the sport ethic norms. 


\section{Introduction}

In sport, some athletes are dedicated to the game to the detriment of other areas of their life (Coakley \& Donnelly, 2009). Although there are damaging consequences for an athlete's wellbeing, this type of dedication is often praised and reinforced within the sport setting (CokerCranney, Watson II, Bernstein, Voelker, \& Coakley, 2018). Thus, the norms in sport are unique and may result in the permission and encouragement of maladaptive behaviours such as drastic weight management strategies (Coker-Cranney et al., 2018), playing through injury (Coakley \& Donnelly, 2009) or using performance-enhancing substances (Goulet, Valois, Buist, \& Côté, 2010). The expectations that guide the "win at all cost attitude" have been termed "sport ethic" (Hughes and Coakley, 1991).

The sport ethic is conceptualized as "a set of norms accepted as the dominant criteria for defining what it means, in their social worlds, to be defined and accepted as an athlete in power and performance sports" (Coakley \& Donnelly, 2009, p.155). Hughes and Coakley (1991) have suggested four norms where each represents an ideal and taken together capture the essence of the sport ethic. They based their suggestion on "informal reports from athletes and from coaches in coaching education programs, combined with information from autobiographies of numerous sport figures" (p.309). The first norm is that being an athlete involves making sacrifices for the game. In this context, priority must be given to the sport to the detriment of any other interests. The athlete must show unwavering commitment and meet expectations. This norm also includes multiple sacrifices that must be made for the sport or the team. The second norm is that being an athlete involves striving for distinction. This norm refers to the notion of relentlessly seeking to improve and achieve perfection regardless of what it takes. The third norm is that being an athlete involves accepting risks and playing through pain. This norm points to the idea that an athlete is 
expected to accept and overcome pressure, pain or fear. Some coaches celebrate athletes who play whilst injured to demonstrate to others what is expected from them (Coakley \& Donnelly, 2009). The fourth norm is that being an athlete involves refusing to accept limits in the pursuit of possibilities. This norm refers to the idea of pursuing one's athletic dream without question. For a detailed discussion about the sport ethic concept, please see Coker-Cranney et al. (2018) and Coakley and Donnelly (2009).

The pioneer work of Hughes et Coakley (1991) has led to the study of extreme behaviors in sport when athletes have overconformed to the four norms of the sport ethic. This overconformity is defined as accepting the norms of the sport ethic without being critical and when athletes are ready to conform to them at an extreme level (Coakley \& Donnelly, 2009, p. 154). Qualitative studies have reported that athletes who overconformed to those norms were engaged in problematic behaviours such as disordered eating, doping, hazing and training while injured (Budziszewski, 2019; Coker-Cranney et al., 2018; Tibbert, Anderson, \& Morris, 2015). The sport ethic was also considered as a contributing factor to violence in sport (Kavanagh, 2014; Parent \& Fortier, 2018; Young, 2012).

To our knowledge, studies using the concept of sport ethic have essentially examined problematic behaviors by athletes (e.g. doping or hazing) or issues in sport (e.g. maltreatment of athletes) with qualitative designs (Berg, Migliaccio, \& Anzini-Varesio, 2014; Coakley \& Donnelly, 2009; Coker-Cranner et al., 2018; Kavanagh, Brown, \& Jones, 2017). These behaviours have been explained in light of the theory of Hughes and Coakley (1991) rather than testing the four factors in statistical models. The concept of sport ethic was theoretically developed based on qualitative data that were collected from various athletes involved in sports at various levels 
(Coker-Cranney et al. 2018). Coker-Cranney et al. (2018) recently stressed the need for the development and validation of an instrument that assesses a young athlete's level of conformity to sport ethic norms. Such an instrument will allow better understanding of how conformity to the sport ethic norms is linked with many behaviour problems discussed earlier in this article. Examining conformity in young athletes will also help develop early interventions to minimize the effects of overconformity. Therefore, the objectives of the present study were to (1) develop and begin an initial factor validation of the Conformity to the Sport Ethic Scale (CSES), a scale assessing the conformity of teenage athletes from all competition levels to these sport ethic norms and (2) examine the generalizability and measurement invariance of the resulting factor structure across boys and girls.

\section{Methods}

\section{Participants and Procedures}

A convenience sample of French-Canadian athletes, between 14 and 18 years and who were involved in an organized sport, were recruited through various recruitment strategies (e.g. social media, mailing lists). Eligible participants were provided with access to a hyperlink to electronically sign a consent form followed by an anonymous survey hosted by a secured website (Qualtrics). This project was approved by the Research Ethics Committee of Laval University.

A total of 1298 athletes met inclusion criteria and began the online survey. Among these, 1096 (83.4\%) completed the CSES and were included in this study. The final sample consisted of 792 girls (72.3\%) and 304 boys (27.7\%). Participants' age ranged from 14 to 18 years, with a mean of 15.31 years $(S D=1.09)$. Most reported that they practice one competitive sport $(61.9 \%, n=$ $678)$ with $38.1 \%(n=418)$ reporting at least two competitive sports. Participants reported that they began to practice their sport at a mean age of $7.71(S D=3.42)$. A wide range of sports were 
referenced, the most common being: soccer $(21.3 \%, n=233)$, volleyball $(13.3 \%, n=146)$, swimming $(10.8 \%, n=118)$, ice hockey $(9.9 \%, n=108)$, basketball $(8.0 \%, n=88)$, track and field $(7.0 \%, n=77)$, cheerleading $(6.8 \%, n=74)$, and American football $(5.4 \%, n=56)$. A total of $26.6 \%(n=292)$ reported that they were competing in their sport at a local or regional/interregional level, $46.5 \%(n=510)$ at a provincial level, $20.6 \%(n=226)$ at a national level, and $5.2 \%(n=57)$ at an international level. A total of $14.3 \%(n=157)$ of athletes reported that they practiced their sport less than five hours a week, 37.4\% $(n=410)$ between 6 and 10 hours a week, $26.5 \%(n=$ 290) between 11 and 15 hours a week, 14.0\% $(n=153)$ between 16 and 20 hours a week, and 7.3\% $(n=86)$ more than 20 hours a week.

\section{Measures}

Item Development. The development of the items was based on the steps proposed by DeVellis (2012). Guided by Hughes and Coakley's theoretical framework (1991), an initial pool of 24 items was developed by the research team to measure the four components of the sport ethic. For each of these four subscales, six items were created. These items asked participants to rate their level of agreement with each statement on a 4-point Likert scale ranging from $1=$ strongly disagree to $4=$ strongly agree. Three items were reversed to control for agreement in responses.

Four independent French-speaking judges with expertise in sport research (morality in sport, sport sociology, sport injuries and violence) evaluated the initial pool of 24 items. They received the article of Hughes \& Coakley (1991) and definitions for each of the four norms. They were asked to rate each item on a scale from 1 to 4 in terms of relevance $(1=$ not relevant to $4=$ very relevant $)$, brevity $(1=$ not concise to $4=$ perfectly concise $)$, and clarity $(1=$ not clear to $4=$ perfectly clear). All items were mostly rated as relevant (judges $M=2.25$ to 4.00), brief (judges 
$M=2.50$ to 4.00 ), and clear (judges $M=2.75$ to 4.00 ). Even if items were not rated unanimously as irrelevant, not concise or unclear, judges suggested to combine two items. All 23 items were retained. Cognitive interviews were then conducted with seven young athletes between 14 and 17 years. The athletes were asked to explain how they interpreted and responded to the 23 items. Responses from athletes were used to adapt items for comprehension and wording.

\section{Statistical Analyses}

To test the factor structure underlying the CSES, we conducted exploratory structural equation modeling (ESEM; Asparouhov \& Muthén, 2009) using Mplus version 8.0 (Muthén \& Muthén, 1998-2015). There were no missing data as participants were required to answer all items in the online questionnaire. Based on Hughes and Coakley's theoretical framework (1991), the scale was developed to assess the four components of the sport ethic; however, to compare this model with other possible factor structure, a one to five-factor structure was tested. However, compared with CFA where all cross-loadings are indicated as zero, ESEM is less restrictive since all factor loadings are estimated such that each item is free to cross-load onto other factors as in EFA (Asparouhov \& Muthén, 2009; Marsh, Morin, Parker, \& Kaur, 2014). The oblique geomin rotation and the weighted least squares mean and variance-adjusted (WLSMV) estimator (Asparouhov \& Muthén, 2010) were used. The invariance of the measurement model across genders was also examined by comparing the configural invariance model, where the model was freely estimated, to a weak invariance model, where equality constraints were added on the factor loadings across boys and girls (Meredith \& Teresi, 2006). Based on Kline's guidelines (2011), an overall model fit was evaluated by considering several fit indices: the comparative fit index (CFI), Tucker-Lewis fit index (TLI), and root mean square error of approximation (RMSEA). CFI and 
TLI values greater than .90 and .95 typically reflect acceptable and excellent fit and RMSEA values of less than .08 and .05 reflect a reasonable and close fit to the data (Hu \& Bentler, 1999). Approximate fit indices that perform well under the WLSMV estimation and that are sample size independent given the large sample size were considered (Marsh, Hau, \& Grayson, 2005). For the invariance test across genders, a change in CFI of less than .01 and a change in RMSEA of less than .015 between the configural and weak invariance model support the more parsimonious model. After identification of the best number of factors, descriptive and correlational analyses were performed with the Statistical Package for the Social Sciences (SPSS 24.0).

\section{Results}

\section{Exploratory Structural Equation Model}

The ESEM was estimated with a one to five-factor structure. The one-factor model, $\chi^{2}(230)$ $=2732.63, p<.001 ;$ RMSEA $=.100,90 \% \mathrm{CI}[.096$ to .103$] ; \mathrm{CFI}=.798 ; \mathrm{TLI}=.77$, and the twofactor model, $\chi^{2}(208)=1347.64, p<.001 ; \mathrm{RMSEA}=.071,90 \% \mathrm{CI}[.067$ to .074$]$; CFI $=.908$; TLI $=.888$, yielded unsatisfactory fit indices. Fit indices continued to improve with an increasing number of factors, reaching a satisfactory level for solutions including three factors or more: threefactor: $\chi^{2}(187)=1011.17, p<.001$; RMSEA $=.063,90 \%$ CI $[.060$ to .067$]$; $\mathrm{CFI}=.934$; TLI $=$ .910 ; four-factor: $\chi^{2}(167)=705.68, p<.001$; RMSEA $=.054,90 \%$ CI[ .050 to .058$]$; CFI $=.957$; $\mathrm{TLI}=.934$; five-factor: $\chi^{2}(148)=533.19, p<.001$; RMSEA $=.049,90 \%$ CI $[.044$ to .053$]$; CFI $=$ $.969 ; \mathrm{TLI}=.947$. The increase in fit indices plateaued between the four and five-factor model, with RMSEA 90\% confidence demonstrating an overlap between the four and five-factor solution. 
This suggested a discontinuation in increasing the number of factors. However, the four and fivefactor models resulted in an empty factor on which no items had main loadings over .30 and no cross-loadings suggesting these additional factors were not meaningful and that the more parsimonious three-factor models should be chosen. After an examination of the chosen solution (i.e. the three-factor model), three items were removed because they had values below .20 on all factors. Results of this new three-factor model with 20 items yielded acceptable fit indices: $\chi^{2}(133)$ $=730.06, p<.001 ; \mathrm{RMSEA}=.064,90 \% \mathrm{CI}[.059$ to .069$] ; \mathrm{CFI}=0.949 ; \mathrm{TLI}=.927$.

Standardized factor loadings and correlations between factors of the three-factor solution are reported in Table 1. This solution was composed of three conceptually meaningful factors reflective of the underlying CSES construct. The first factor consisted of six items that measure striving for distinction behaviours. All of these items were developed for this subscale. The second factor consisted of four items that measure self-sacrifice for the sport. Two items that were developed for this subscale (items \#2 and \#6) loaded strongly onto the third factor. These items were retained as their meanings were consistent with the third factor. The third factor consisted of ten items that measure refusing to accept limits. This factor included items that were developed for the 'refusing to accept limits' and 'accepting risks and playing through pain' subscales. Thus, in this new subscale, limits are represented in different forms including physical limits and pain. The measurement invariance of this three-factor solution across genders was then estimated. The configural and weak invariance model provided a satisfactory level of approximate fit to the data with CFI and TLI $>.95$ and RMSEA $<.05$. The comparison of the fit indices of the configural invariance model to the weak invariance model indicated that the model is invariant across genders as shown by the difference in the CFI and RMSEA, $\Delta$ CFI $=.004 \leq .01, \Delta \mathrm{RMSEA}=-.007 \leq .015$. Thus, this model was consistent for both boys and girls. 
Internal consistency of these subscales was acceptable with ordinal coefficient alphas using polychoric correlations (Zumbo, Gadermann, \& Zeisser, 2007) of .85 for the striving for distinction subscale, .72 for the self-sacrifice subscale, and .76 for the refusing to accept limits subscale. An average of the items was taken to calculate total scores for each subscale with a mean of 2.70 (SD $=0.73$; range $=1$ to 4$)$ for the striving for distinction subscale, $2.28(S D=0.77$; range $=1$ to 4$)$ for the self-sacrifice subscale, and $3.17(\mathrm{SD}=0.45$; range $=1.20$ to 4$)$ for the refusing to accept limits subscale. Correlations between these three subscales were significant and varied between $r=.40$, $p<.001$ to $r=.52, p<.001$.

\section{Discussion}

These results demonstrate that the CSES is not a four-factor structure in the current sample, but rather a three-factor structure that was consistent for both boys and girls, namely striving for distinction, self-sacrifice, and refusing to accept limits. Some items developed for the "accepting risks and playing through pain" subscale were associated with the items from the "refusing to accept limits" subscale. Refusing to accept limits could also mean not accepting physical and cognitive limits, such as injury, pain and fear. When examining the four initial dimensions of the sport ethic proposed by Hughes and Coakley (1991), the descriptions for both refusing to accept limits and accepting risk/playing through pain were quite similar. Although items were developed specifically for pain and injury, those items clearly fit with the dimension referred to as "refusing to accept limits" in this sample. As those initial dimensions of the sport ethic had not yet been statistically tested for their structure and that we created items from a qualitative theoretical model, these results may help to improve the model of Hughes and Coakley (1991). 
The CSES was designed for young athletes aged between 14 and 18 years participating in any type of sport and level of competition. Thus, the items are general and non-specific to sport subcultures. Our results also indicated that the factor structure was consistent for both boys and girls. The CSES has the advantage of allowing for comparisons between sports (e.g., aesthetic sports, weight-category sports) and gender about norms endorsed and problems encountered by athletes (e.g., playing while injured, doping). In this study, the CSES was developed to measure the conformity of athletes to the sport ethic, but other actors of the sport system (e,g., coaches, parents) may also have endorsed those norms (Coakley \& Donnelly, 2009; Kavanagh, 2014; Stirling \& Kerr, 2014). When those "actors" endorse them at an extreme level, it could encourage athletes to conform and adopt risky behaviours (Young, 2012) and conceal athlete abuse (Kavanagh, 2014). Future research should adapt the CSES to other actors in sport and validate the scale on a sample of adult athletes. Future research should also explore links between conformity to the sport ethic and health-damaging behaviours to allow for the establishment of a threshold of under-conformity (i.e., rejection of the sport ethic) and over-conformity (i.e., uncritical conformity to the sport ethic) (Hughes \& Coakley, 1991). Finally, the CSES could also serve as a surveillance tool used in regular time-based intervals to evaluate the impact of prevention strategies aimed at changing norms in the sport culture because it is known that a strong adhesion to those norms may have problematic effects on behaviors in athletes.

Future research on the CSES should use a representative sample for generalization purposes. Also, because only a single measurement was obtained, the test-retest reliability was not examined. Future research should examine convergent validity, with measures such as self-esteem and athletic identity. It has been suggested that athletes who have low self-esteem or for whom their identity is engulfed within their athletic role are more likely to strictly adhere to the norms of 
the sport ethic (Coakley \& Donnelly, 2009). In conclusion, the development and initial validation in this study is the first step to measure conformity to the sport ethic and will allow for further research in this area.

\section{Acknowledgements}

The authors would like to acknowledge all team members, particularly Catherine Flynn, Caroline

D’Amours, Michaël Bégin, Judith Kotiuga, Sophie-Émilie Poulin-Lapierre, Mélina Fortin, Carolane Fournier, Francis Lefèbvre and Marilou Gauthier. We also thank every young athlete who took the time to participate in this study.

\section{References}

Asparouhov, T., \& Muthén, B. (2009). Exploratory structural equation modeling. Structural Equation Modeling, 16, 397-438.

Asparouhov, T., \& Muthén, B. O. (2010). Weighted least squares estimation with missing data. Los Angeles, CA: Muthén \& Muthén. Retrieved from: http://www.statmodel.com/download/GstrucMissingRevision.pdf

Berg, E.C., Migliaccio, T.A. \& Anzini-Varesio, R. (2014). Female Football Players, the Sport Ethic and the Masculinity-Sport Nexus. Sport in Society, 17, 176-189.

Budziszweski, R. (2019). 'Get Tough!' : A Case Study on the Development of the Sport Ethic in Youth Lacross. All Graduate Plan B and other Reports, Utad State University.

Coakley, J., \& Donnelly, P. (2009) Sports in society: issues and controversies. New York : McGraw-Hill.

Coker-Cranney, A., Watson II, J., C., Bernstein, M., Voelker, D.K., \& Coakley, J. (2018). How 
far is too far? Understanding identity and overconformity in collegiate wrestlers. Qualitative Research in Sport, Exercise and Health, 10(1), 92-116. doi:10.1080/2159676X.2017.1372798

DeVellis, R.F. (2012). Scale Development: Theory and Applications. USA: Sage.

Goulet, C., Valois, P., Buist, A., \& Côté, M. (2010). Predictors of the use of performanceenhancing substances by young athletes. Clinical Journal of Sport Medicine 20, 243-248.

Hu, L.-T., \& Bentler, P. M. (1999). Cutoff criteria for fit indexes in covariance structure analysis: Conventional criteria versus new alternatives. Structural Equation Modeling, $6(1), 1-55$.

Hughes, R., \& Coakley, J. (1991). Positive deviance among athletes : the implications of overconformity to the sport ethic. Sociology of Sport Journal, 8 (4): 307-325.

Kavanagh, E.J. (2014). The Dark Side of Sport : Athlete Narratives of Maltreatment in High Performance Environments (Doctoral dissertation). Retrieved from http://eprints.bournemouth.ac.uk/21488/1/PhD\%20EK\%20Final\%20(2).pdf

Kavanagh, E., Brown, L., Jones, I., (2017). Elite athletes' experience of coping with emotional abuse in the coach-athlete relationship. Journal of Applied Sport Psychology, 29 (4), 402-417.

Kerr, G., \& Stirling, A. (2014). Applying a critical ecological approach to the issue of athlete abuse in sport. In Schinke, R.J., \& McGannon, K.R. (Eds). The Psychology of SubCulture in Sport and Physical Activity. London: Routledge, pp. 17-30.

Kline, R. B. (2011). Principles and practice of structural equation modeling (3rd ed.). New York, NY: Guilford Press. 
Marsh, H. W., Hau, K., \& Grayson, D. (2005). Goodness of fit in structural equation models. In A. Maydeu-Olivares \& J. J. McArdle (Eds.), Contemporary psychometrics: A festschrift for Roderick P. McDonald (pp. 275-340). Mahwah, NJ: Erlbaum.

Marsh, H. W., Morin, A. J. S., Parker, P. D., \& Kaur, G. (2014). Exploratory structural equation modeling: An integration of the best features of exploratory and confirmatory factor analysis. Annual Review of Clinical Psychology, 10, 85-110. doi: 10.1146/annurevclinpsy-032813-153700

Meredith, W., \& Teresi, J. A. (2006). An essay on measurement and factorial invariance. Medical Care, 44, 69-77.

Muthén, L. K., \& Muthén, B. O. (1998-2015). Mplus user’s guide. Seventh Edition. Los Angeles, CA: Muthén \& Muthén.

Parent, S., \& Fortier, K. (2018). Comprehensive overview of the problem of violence against athletes in sport. Journal of Sport and Social Issues, 42(2), 227-246. DOI: 10.1177/0193723518759448Tibbert, S. J., Andersen, M. B., \& Morris, T. (2015). What a difference a "Mentally Toughening" year makes: The acculturation of a rookie. Psychology of Sport and Exercise, 17, 68-78. Retrieved from http://www.sciencedirect.com/science/article/pii/S1469029214001484.

doi:https://doi.org/10.1016/j.psychsport.2014.10.007

Young, K. (2012). Sport, violence and society. New York, NY : Routledge.

Zumbo, B. D., Gadermann, A. M., \& Zeisser, C. (2007). Ordinal versions of coefficients alpha and theta for Likert rating scales. Journal of Modern Applied Statistical Methods, 6, 21-29. 
Table 1

Factor loadings and factor correlations of the three-factor ESEM for conformity to the sport ethic scale (CSES)

\begin{tabular}{|c|c|c|c|}
\hline Items & $\begin{array}{c}\text { Factor } \\
1\end{array}$ & $\begin{array}{c}\text { Factor } \\
2\end{array}$ & $\begin{array}{c}\text { Factor } \\
3\end{array}$ \\
\hline 1. Je considère qu'il n'y a que la première position qui compte. & .526 & -.014 & .086 \\
\hline 5. Je cherche toujours à être meilleur que les autres athlètes. & .862 & -.025 & .142 \\
\hline 9. Je vise avant tout la victoire. & .598 & .016 & .219 \\
\hline 12. Je vise la perfection. & .428 & .058 & .267 \\
\hline 15. Je cherche constamment à être supérieur aux autres athlètes. & .862 & .093 & -.014 \\
\hline 18R. Être meilleur que les autres athlètes m'importe peu. & .704 & .005 & -.046 \\
\hline 10. Je ne me permets pas d'avoir d'autres intérêts qui pourraient nuire à & -.017 & .777 & -.082 \\
\hline 13. Je fais constamment des sacrifices pour être le meilleur athlète possible. & .102 & .554 & .204 \\
\hline 16. Toutes mes décisions sont orientées vers la pratique de mon sport. & -.003 & .818 & .009 \\
\hline 19. Je suis prêt à laisser tomber ce qui est important pour moi afin de conserver ma place dans l'équipe ou dans le club. & -.029 & .666 & .116 \\
\hline 2. Je peux faire n'importe quoi pour prouver mon engagement envers mon sport. & .007 & .185 & .490 \\
\hline 3. J'accepte le risque de me blesser ou d'avoir mal. & -.014 & -.127 & .666 \\
\hline 4. Je tente par tous les moyens de repousser mes limites. & .001 & -.003 & .603 \\
\hline 6. Je suis prêt à tout pour répondre aux attentes de mon entourage (entraîneurs, parents, coéquipiers, partisans, etc.). & .059 & .196 & .460 \\
\hline 7. Je poursuis l'entraînement ou la compétition malgré la présence de douleur ou d'une blessure. & .124 & -.021 & .480 \\
\hline 8. Je peux améliorer mes performances à l'infini. & -.001 & .151 & .317 \\
\hline 11R. Je refuse de poursuivre l'entraînement ou la compétition si j'ai peur de me blesser ou d'avoir mal. & -.058 & -.215 & .502 \\
\hline 14. Lorsque je suis confronté à de nouveaux défis de performance, je refuse d'abandonner malgré ma peur d'échouer. & -.092 & .054 & .517 \\
\hline 17. Je considère qu'il est impensable de céder sous la pression (« chocker $»)$ & .072 & .104 & .306 \\
\hline $\begin{array}{l}\text { 20. Je refuse d'accepter mes propres limites (physiques et psychologiques) lorsqu'il est question d'atteindre mes objectifs } \\
\text { de performance. }\end{array}$ & .105 & .255 & .329 \\
\hline Factor correlations & & & \\
\hline Factor 1 & - & .471 & .283 \\
\hline Factor 2 & - & - & .551 \\
\hline
\end{tabular}

Note. ESEM = exploratory structural equation modeling 